\title{
Structural Characterization of Steatite Vessels of Shadyakh by XRF, XRD and SEM Techniques
}

\author{
Parastoo Masjedi Khak ${ }^{* 1}$, Negar Shirazi ${ }^{2}$, Hasan Nami ${ }^{1}$, Mahdi Hajivaliei ${ }^{3}$ \\ ${ }^{1}$ Assistant Professor of Archeology, Department of Archaeology, University of Neyshabur, Khorasan, IRAN \\ ${ }^{2}$ M.A. in Archeology, University of Neyshabur, Khorasan, IRAN \\ ${ }^{3}$ Associate Professor of Physics, University of Bu-Ali Sina, Hamedan, IRAN
}

Received: 21/05/2018

Accepted: $22 / 11 / 2018$

\begin{abstract}
Using the stones to make tools and vessels dated back to Paleolithic and Neolithic periods. Stones so called soft stones, along with the alabaster, are one of the most famous stones that have been used to produce vessel in Near East, where they are in use currently in different applications. Soft stone vessels reach to highest level of flourishing during the Bronze Age and its geographical exchange area stretches from India in east to Syria in west. Iran, as one of the most important places of this kind of stones, was a potentially center in this trade and archaeological sites such as Tape Yahya and Konar Sandal in Kerman province are some of the most famous sites in making and exporting this kind of objects. Although soft stone vessel making continued during historical to Islamic era, but this industry has been neglected by researchers and archaeologist. In addition, until now morphological and artistic reports and archaeometry studies have focused only on Bronze Age vessels. During six seasons archaeological excavations at an Islamic Archaeological site called Shadyakh near to modern city of Neyshabur (about $2 \mathrm{~km}$ south east of Neyshabur), which its date goes back to Early and middle Islamic period, many cultural objects, like the pottery, glass, metal, bones, human skeletal, plaster, and architectural remains have been discovered. Beside of these samples, several pieces of soft stone vessels were discovered from several archaeological excavations. No evidence of workshop or crafting was reported and according to geological reports around this region, no outcrop of soft stone was seen. Although that these vessels are important, no study have yet been conducted on them. At this research, the vessels have been archaeometrically studied. The main objective of this research was to gain the information about the structural characteristics of soft stone vessels recovered from this site. Before this, Kohl and his collogues in 1979 carried an investigation on large amount of Bronze Age archaeological samples from Middle East. They found several main groups and a mine around Mashhad was recognized. Other researches on soft stones include Razani's M.A and Imami and his colleague's researches on new chlorite mines of Ashin; and Afshari Nezhad and Razani's research on structural characterization and conservation of Jiroft cultural basin's chlorite vessels. The only research on historical and Islamic soft stone vessels was about the effect of cooking conditions on structure of vessels. At this research, totally 16 samples from different seasons of archaeological excavations of Shadyakh were collected and analyzed by XRD, 4 sample analyzed by XRF, and 2 samples by SEM. The results of XRD analysis showed two main groups, while 21 trace elements and 11 chemical compound were detected by XRF. The raw data was studied by Excel statistic software. At this study, overlap graph was prepared according to finding difference or similarity between samples where the results show high similarity among the samples. The SEM and XRD results show that main compounds are Talc, Steatite,
\end{abstract}

\footnotetext{
*Corresponding author: parastomasjedi@yahoo.com
} 
Soapstone, Clinochlore, Graftonite, Dolomite, Britholite and Clinochlore. All samples have these compounds, therefore, it could be concluded that Shadyakh samples come from one geological zone. Keywords: Steatite, Shadyakh, Neyshabur, XRF, XRD, SEM 


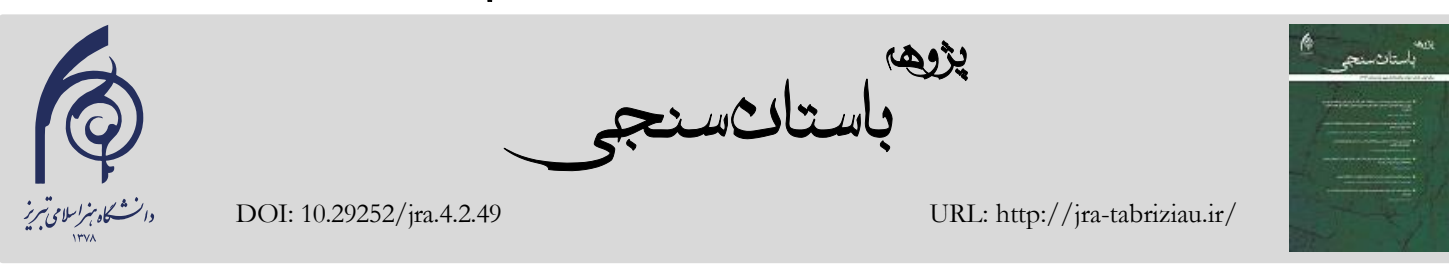

دماله بِرَوهشى

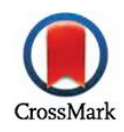

\section{مطالعه ساختارشناسى ظروف سنَّ استاتيتى محوطه شادياخ به روش XRF، و XRD}

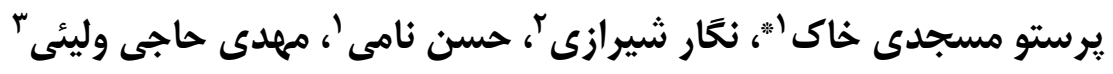

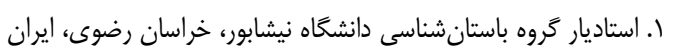

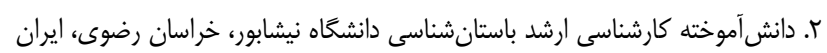

r. دانشيار كروه فيزيك، دانشكاه بوعلى سينا، همدان، ايران انشان

Iس تاريخ يذيرش:

تاريخ دريافت: اسر/N

جكيده

توليد ظروف سنگى از دوران نوسنگى آغاز شد، توليد و استفاده از سنگَهاى كلريت و استاتيت نيز از دوران مفرغ آغاز گرديد. ايران

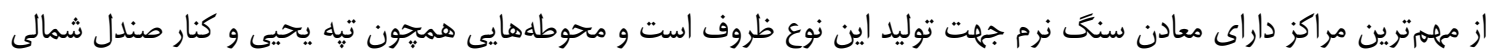

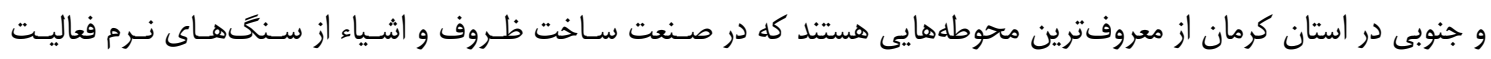

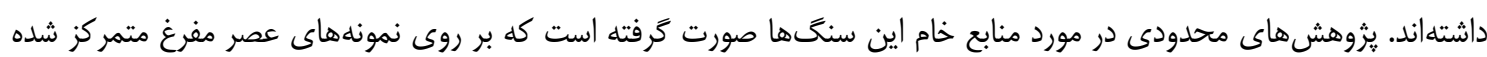

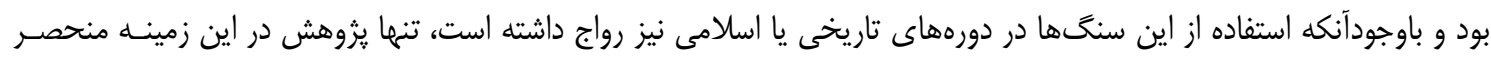

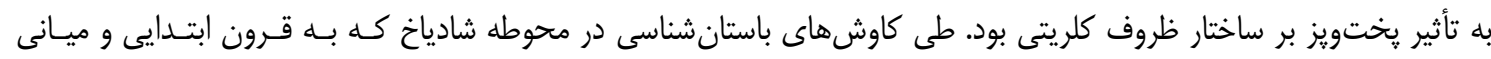

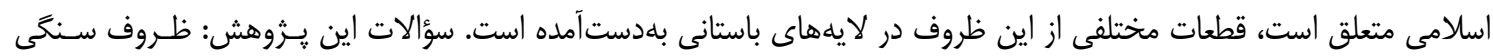

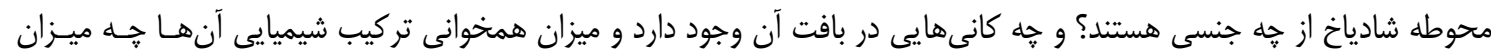

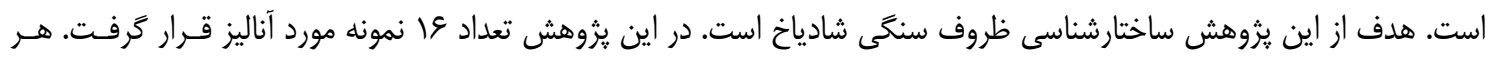

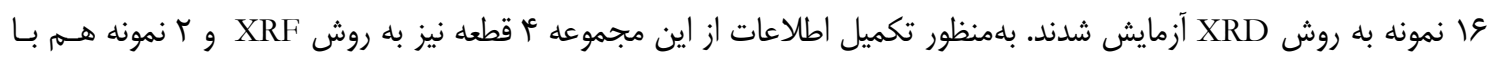

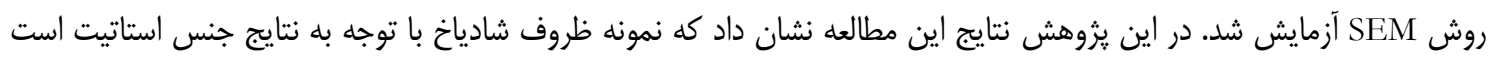

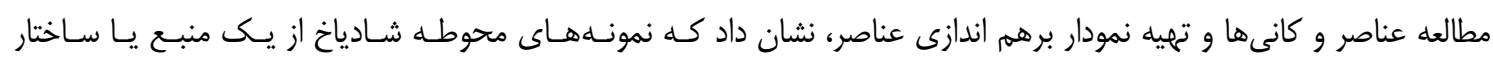
زمينشناسى ساخته شدند.

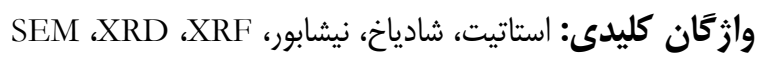

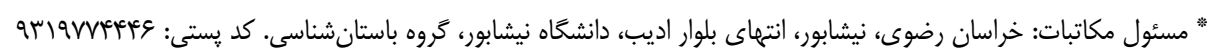

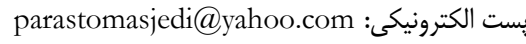

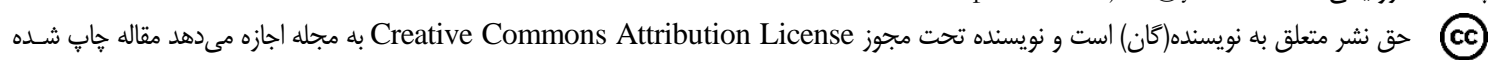
را با ديكران به اشتراك بخذارد منوط بر اينكه حقوق مؤلف اثر حفظ و به انتشار اوليه مقاله در اين مجله اشاره شود. 
در حفارىهاى دوران اسلامى در استان خراسـان خنــدين

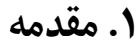

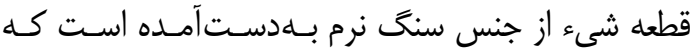

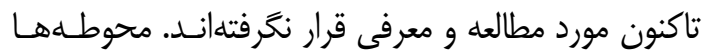

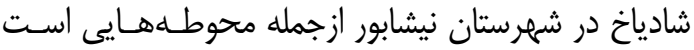

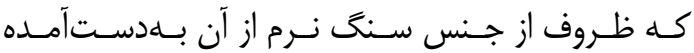

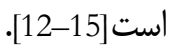

شايد بتوان از علل تداوم اين سنت و صنعت تا امـروز

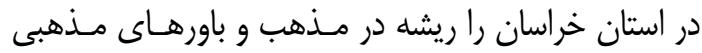
مردم دانست. در دوران اسلامى در احاديث بر اهميت ايـن إنـان

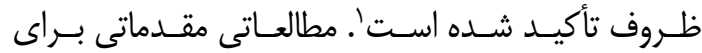

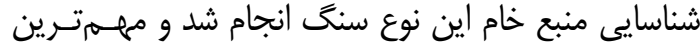

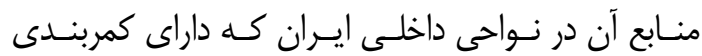

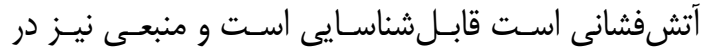
اطراف مشهد كزارش شده است[16].

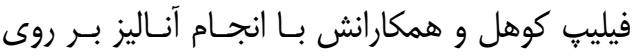
خصيصه شيميايى و فيزيكى اشياء سنگىى، به بحث دربـاره

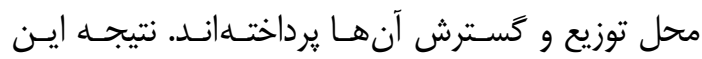

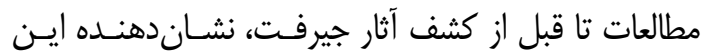
واقعيت بود كه تبه يحيى بلعنوان يكى از مهمترين مراكز

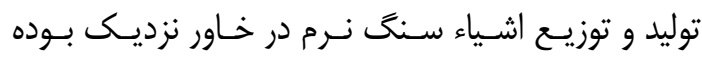

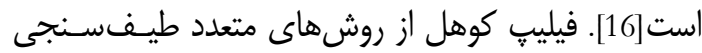

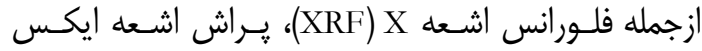

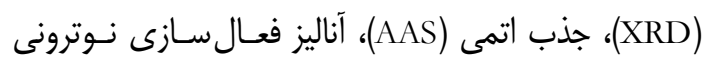

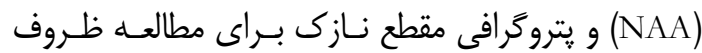

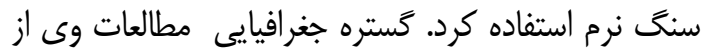

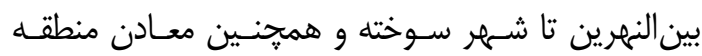

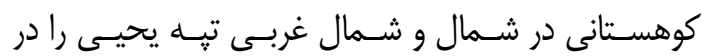

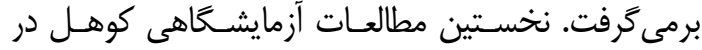

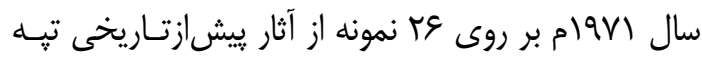
يحيى و معادن اطراف آن، با روش فعال سازى نـوترونى و طيفسنجى اشعه X به انجام رسيد. تا يـيش از مطالعـات

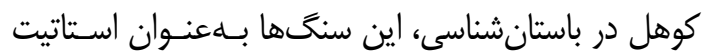

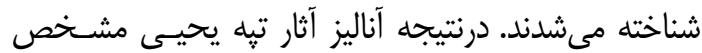

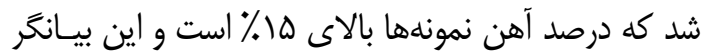

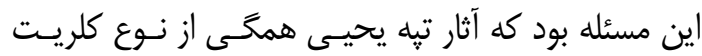

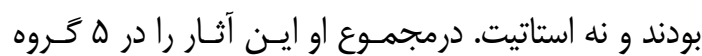

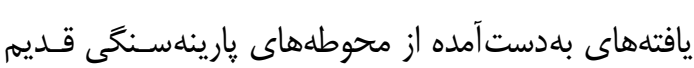

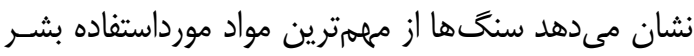

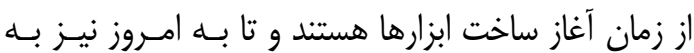

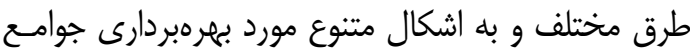

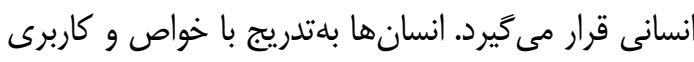
انواع كوناحون سنحَها آشنا شده و در زمينههاى مختلـف از آن استفاده كردند. براى مثال از ابسيدين به دليل جلا و ودان

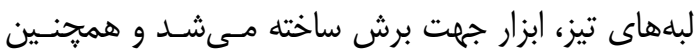

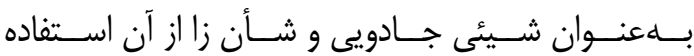

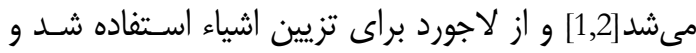

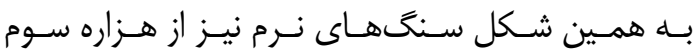

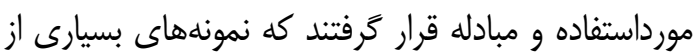
آن از جنوب شرق ايران و سواحل جنوبى دريـاى عمـان و وران

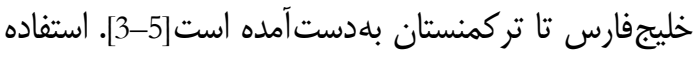

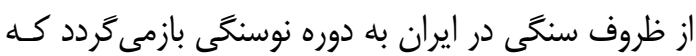

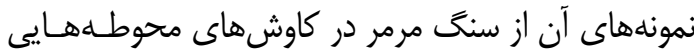

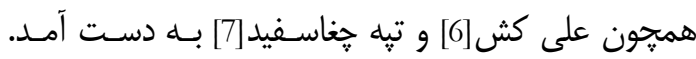
بعدها ظروف ساختهشده از سنَّهاى نرم با كميت زياد از محوطههاى عصر مفرغ فلات مركزى ايران هميجون تبـهـ

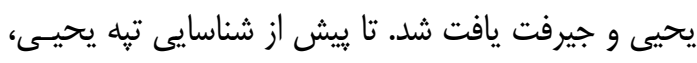

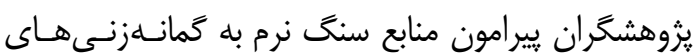

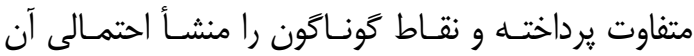

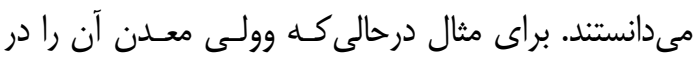

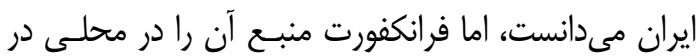
قلمرو سومريان عنوان مىكرد[8]. امـا بـا كـاوش در تيـهـ

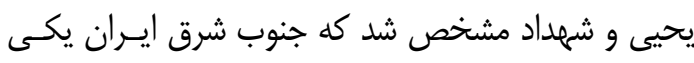

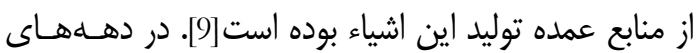

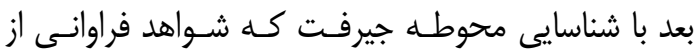

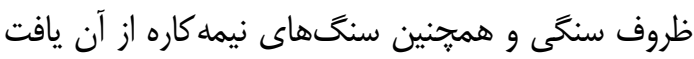
شد، اطلاعات جديدى به دست آمد كه موجب شكل ئيرى يثروهش نوين در اين زمينه شد[10,11].

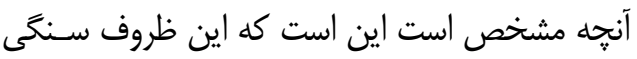

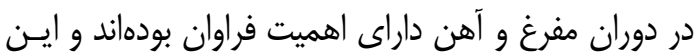

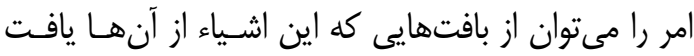
شده است و همجنين كتيبههاى روى اين ظروف دريافت. 
آناليزهــاى XRD و SEM و همجنــين يتروگرافى انجـام

شده است[20].

يزوهش هاى ديخر در زمينه مطالعات ميـانرشـتهاى اله

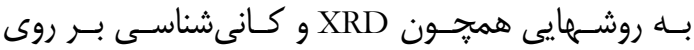

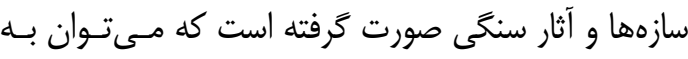

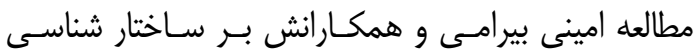

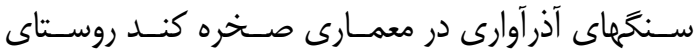
كندوان اشاره كرد[21].

\section{r. محوطه موردمطالعه}

شهرستان نيشابور در استان خراسان رضوى در شمالشرق مورد ايران واقع شده است. ازلحاظ تقسـيمات كشـورى دشـت لتهـ

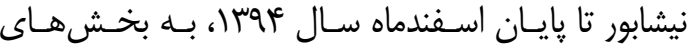

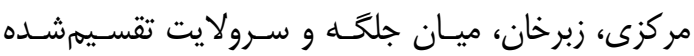

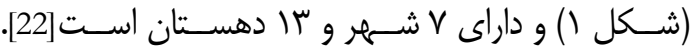

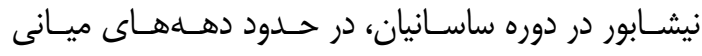

كلريت طبقهبندى كرد[16].

استاتيت داراى ميزان عمدهاى تالك است و به لحاظ

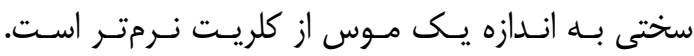
نمونههاى سنَّهاى كلريـت داراى ميـزان بـالايى آهـن

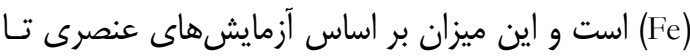

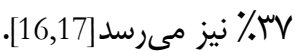

در مطالعهاى رازانى به مطالعه ظروف از جنس سنَ

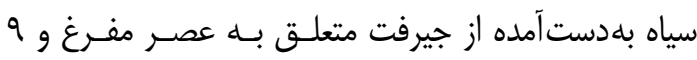

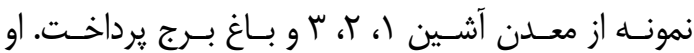

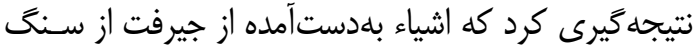
كلريت با فازهاى كلينو كلر و سافرين هستند. اين اشياء بــــ

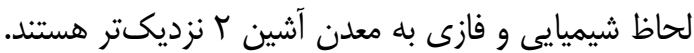

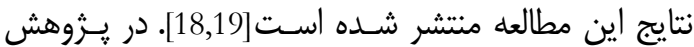
ديخرى افشارىنزاد و رازانى بله مطالعـهـ سـاختار و مرمـت

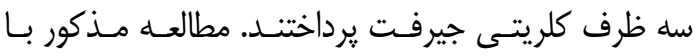

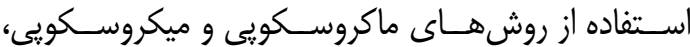

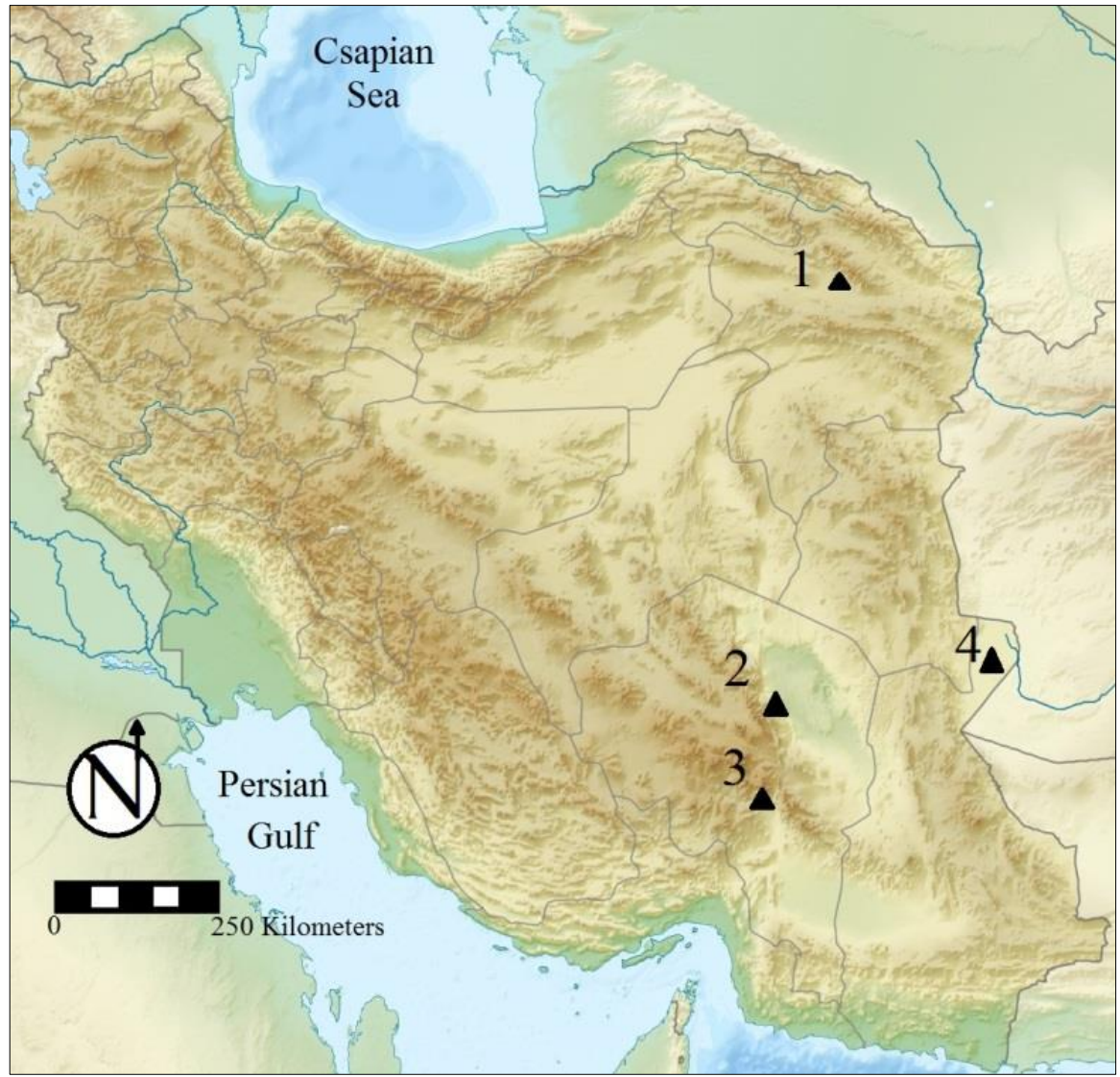

شكل ا: نقشه موقعيت جغرافيايى محوطه شادياخ، I- شادياخ، r- تبه يحيى، س- كنار صندل، أ- شهر سوخته

Fig. 1: geographic position of Shdyakh, 1- Shadyakh, 2- Tape Yahya, 3- Konar Sandal, 4- Shahre Sokhteh 


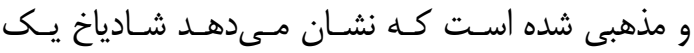

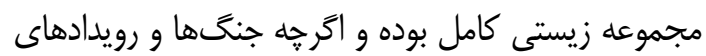

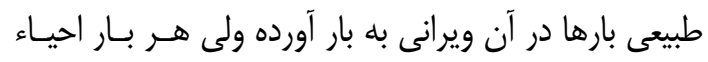

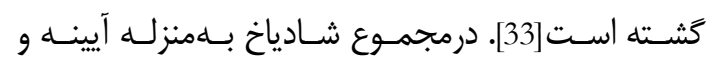

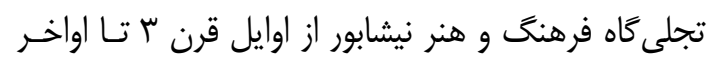

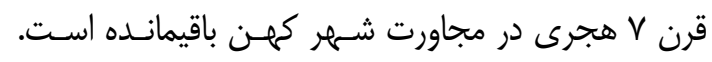

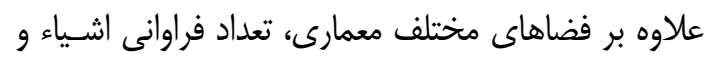

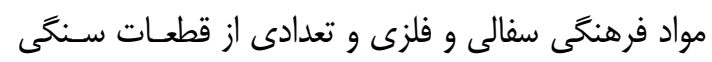

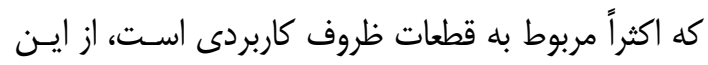

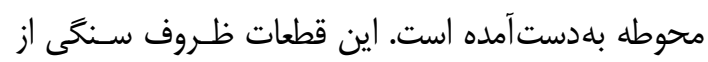

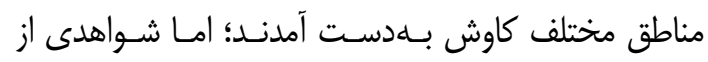

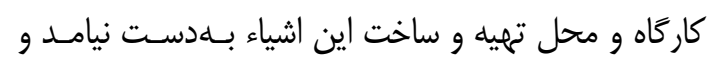

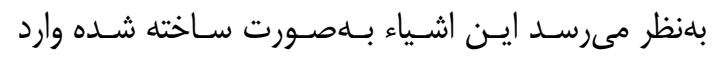
محوطه مىشده است.

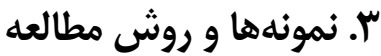

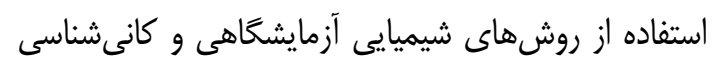

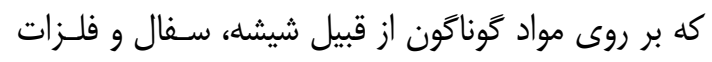

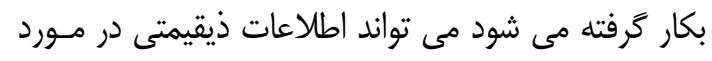

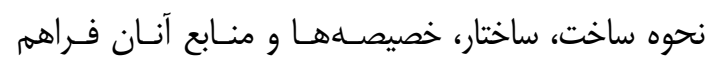

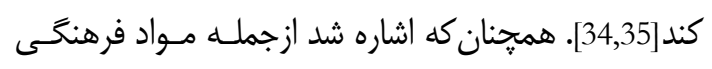

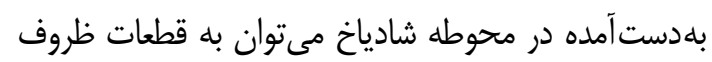

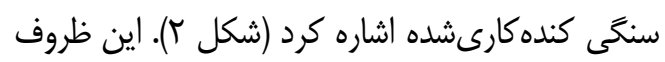

ســدهى سـوم مـيلادى بــه فرمـان شـايور اول تأسـيس

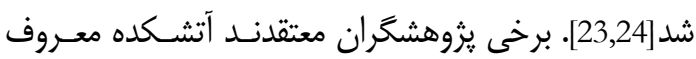

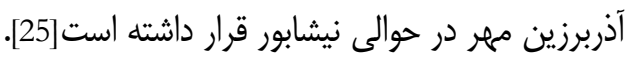
اهميت سياسى اين شهر در دوره اسلامى بـــ دورهاى دئى

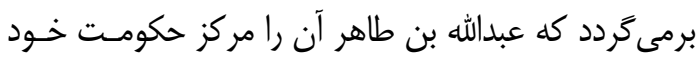

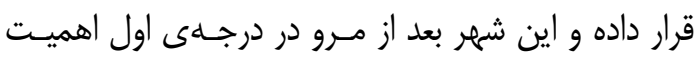

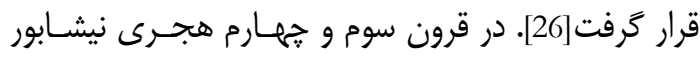

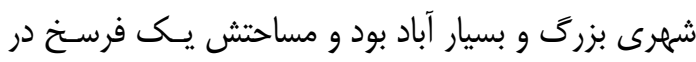

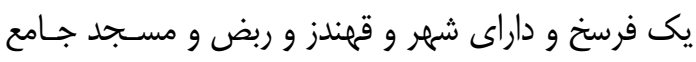

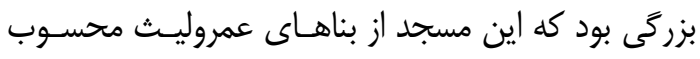

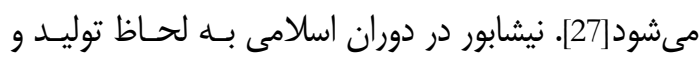

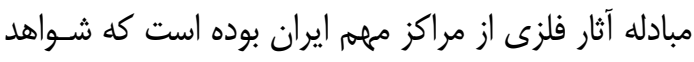

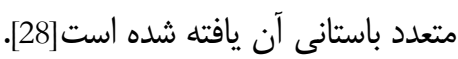

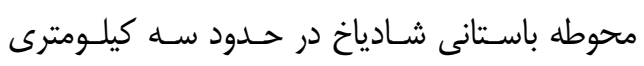
جنوب شرقى شهر فعلى نيشابور و در غرب نيشابور قديم و

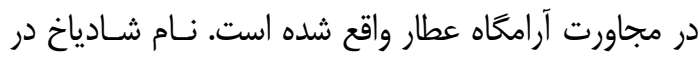
متون مختلف به صورتهاى شاذياخ، شادكاخ، شادى كـاخ،

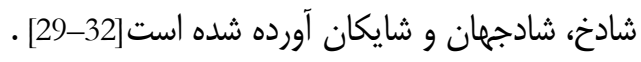

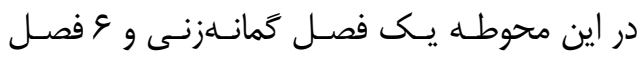

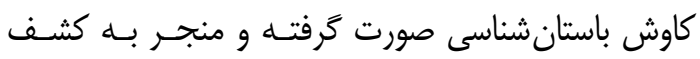
يافتههاى باستان شناسى اعم از بقاياى معمارى و تزئينـات

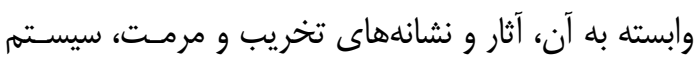

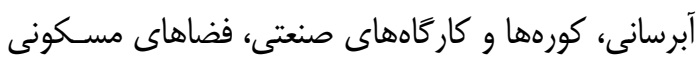

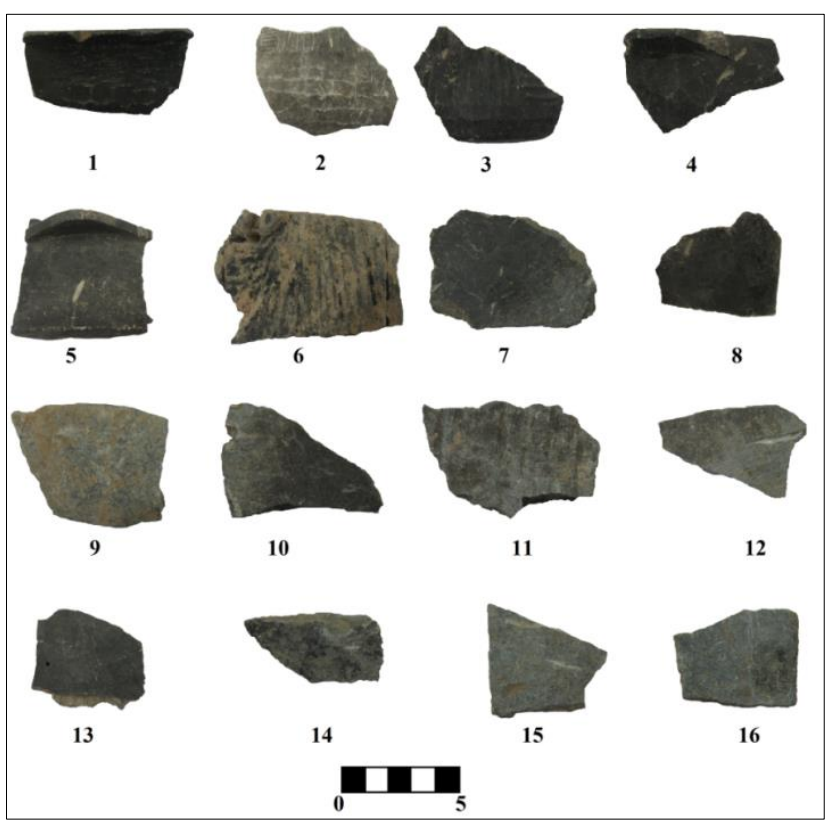

شكل r: نمونه قطعات ظروف سنخى محوطه شادياخ باستانى

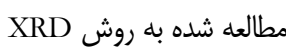
Fig. 2: archaeological stone vessels fragments of Shadyakh analysed by XRD

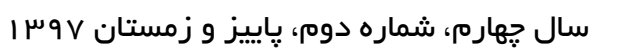


نمونههاى باستانى آزمايششده توسط XRF، از ميان نمونههاى آزمايش شده XRD انتخاب شدند. نمونه شـماره

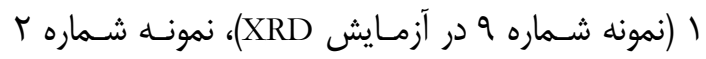

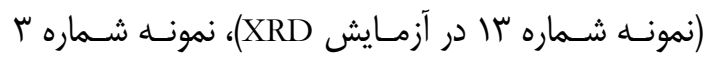

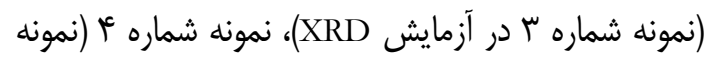

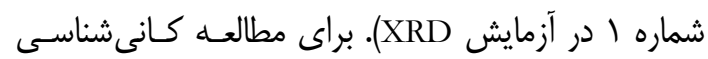

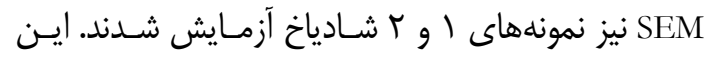

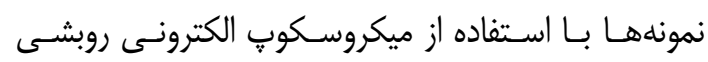

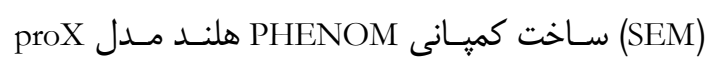
بخش متالوزى دانشكاه آزاد نيشابور مطالعه كَرديــــ نتسايج

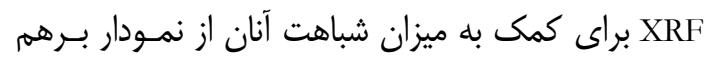

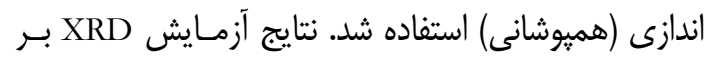
اساس فازها بهصورت جدول و نمودار خوشهاى نشان داده

\section{f أنتايج و بحث}

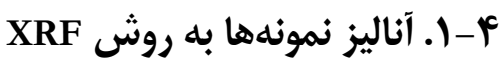

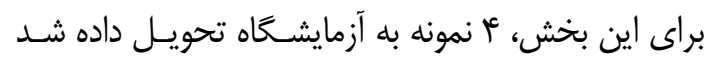

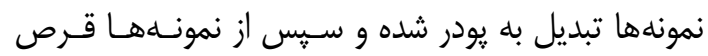

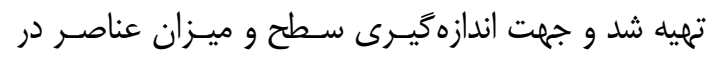

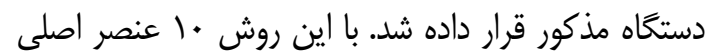

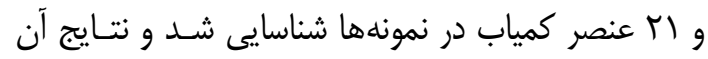

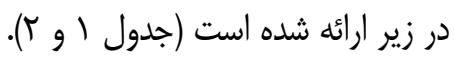

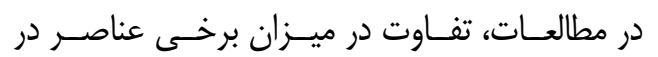
نمونهها را بلعنوان شاخصهاى براى تميز دادن تعداد منابع تأمين سنگ خام به كار مىبرند.

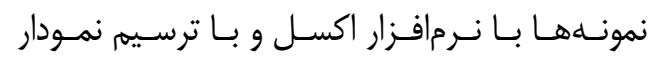
همبوشانى بر اسـاس عناصـر اصـلى و كميـاب مشـخص

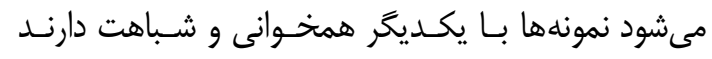

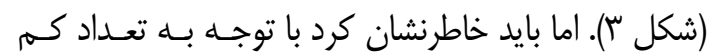

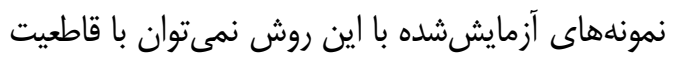

سنگى در فرهنَ عامه به نام ظروف ديزى و در خراسـان

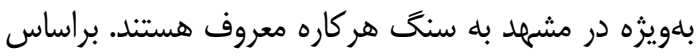

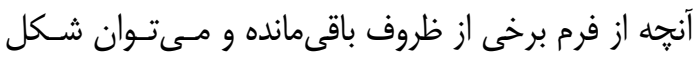

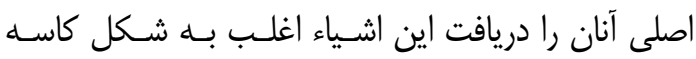

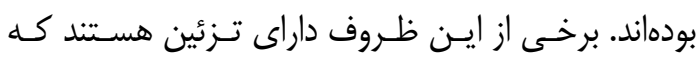

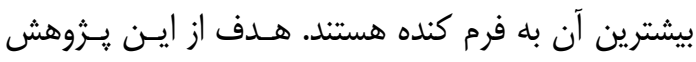

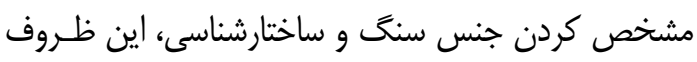

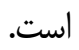

در اين يزوهش نغارنـدكان جهـت شناسـايى جــس

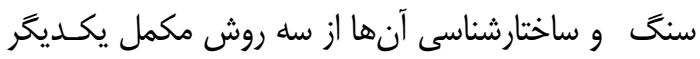

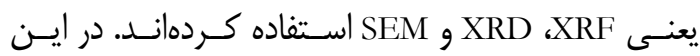
مطالعه عا نمونه از قطعات ظروف سنكى محوطه شـادياخ

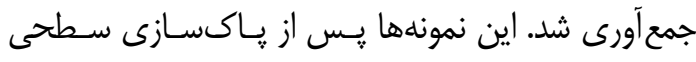

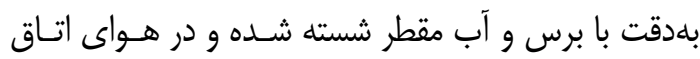

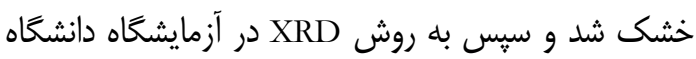
بوعلى سيناى همدان آزمايش گر ديد. دستخاه مورداسـتفاده

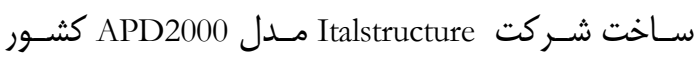

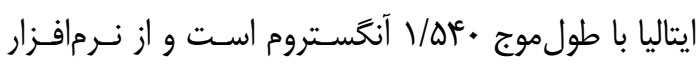

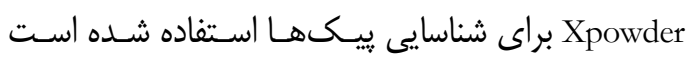
(شكل عا). (ش)

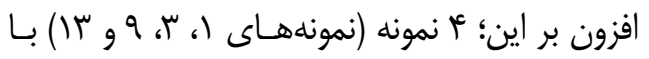
دستخاه XRF شركت كانسارهاى بينالود تهـران آزمـايش

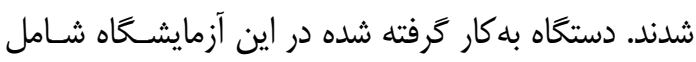

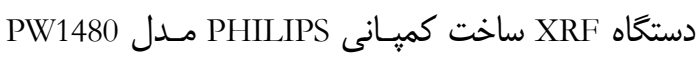

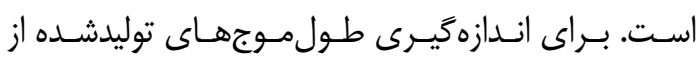

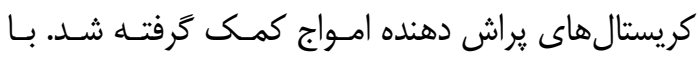

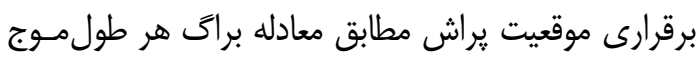

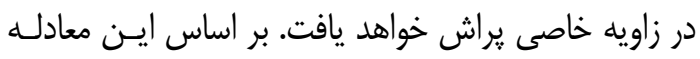
طولموج محاسبهشده و نتيجه آن شناسايى عنصر مربوطه است. با برقرارى خط كاليبراسيون ميزان عنصر مورد نظـر

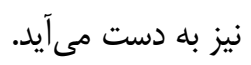

جدول (: نتايج تركيب عناصر اصلى بر اساس آناليز نمونههاى آزمايشى با روش XRF (برحسب درصد)؟ Table 1: results of analysis by XRF (\%)

\begin{tabular}{|l|l|l|l|l|l|l|l|l|l|l|c|}
\hline L.O.1 & $\mathrm{P}_{2} \mathrm{O}_{5}$ & $\mathrm{MnO}$ & $\mathrm{TiO}_{2}$ & $\mathrm{MgO}$ & $\mathrm{K}_{2} \mathrm{O}$ & $\mathrm{Na}_{2} \mathrm{O}$ & $\mathrm{CaO}$ & $\mathrm{Fe}_{2} \mathrm{O}_{3}$ & $\mathrm{Al}_{2} \mathrm{O}_{3}$ & $\mathrm{SiO}_{2}$ & Samples \\
\hline 17.54 & 0.050 & 0.159 & 0.376 & 26.87 & 0.02 & 0.09 & 4.21 & 11.12 & 3.98 & 34.86 & 1 \\
\hline 17.26 & 0.025 & 0.138 & 0.382 & 25.36 & 0.03 & 0.08 & 5.96 & 10.18 & 3.84 & 36.12 & 2 \\
\hline 14.18 & 0.068 & 0.181 & 0.498 & 26.02 & 0.02 & 0.07 & 3.93 & 10.82 & 4.67 & 38.74 & 3 \\
\hline 16.05 & 0.049 & 0.169 & 0.482 & 24.26 & 0.02 & 0.12 & 5.89 & 10.35 & 4.78 & 37.15 & 4 \\
\hline
\end{tabular}


جدول ז: نتايج عناصر كمياب موجود در نمونهها بر اساس آناليز بلوسيله دستخاه XRF (برحسب ppm).

Table 2: results of analysis by XRF (ppm)

\begin{tabular}{|c|c|c|c|c|c|c|c|c|c|c|c|c|c|c|c|c|c|c|c|c|c|}
\hline Ga & Mo & Th & U & As & Co & $\mathrm{Rb}$ & $\mathrm{Y}$ & $\mathrm{Zr}$ & $\mathrm{W}$ & $\mathrm{La}$ & $\mathrm{Ce}$ & $\mathrm{V}$ & $\mathrm{Cr}$ & $\mathrm{Ni}$ & $\mathrm{Pb}$ & $\mathrm{Zn}$ & $\mathrm{Cu}$ & $\mathrm{Sr}$ & $\mathrm{Ba}$ & $\mathrm{Cl}$ & Samples \\
\hline 21 & 4 & 4 & 10 & 142 & 120 & 8 & 9 & 274 & 2 & 2 & 5 & 117 & 3172 & 1814 & 2 & 106 & 11 & 163 & 17 & 38 & 1 \\
\hline 23 & 2 & 4 & 4 & 11 & 108 & 8 & 11 & 352 & 1 & 8 & 15 & 118 & 2651 & 1501 & 1 & 91 & 24 & 11 & 12 & 102 & 2 \\
\hline 21 & 3 & 3 & 3 & 13 & 84 & 8 & 9 & 238 & 1 & 3 & 9 & 152 & 2768 & 1989 & 1 & 100 & 43 & 11 & 5 & 26 & 3 \\
\hline 23 & 2 & 5 & 5 & 18 & 72 & 9 & 6 & 257 & 2 & 2 & 4 & 133 & 2944 & 1602 & 9 & 89 & 31 & 82 & 4 & 21 & 4 \\
\hline
\end{tabular}

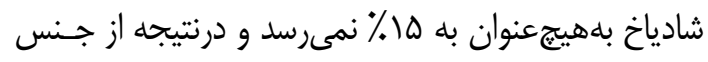
استاتيت يا تالك هستند [16,17].

\section{XRD F-T} عا قطعه كاوشهاى شـر باسـتانى شـادياخ بـا دسـتخاه

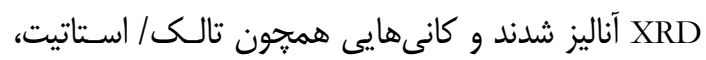

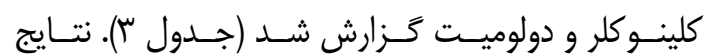
بلهصورت خوشهبندى بله نمايش كذاشـته شــند تـا بتـوان برداشت صحيحى از نتايج XRD داشت. بر اساس تركيبات موجود در نمونهها شـايد بتـوان دو داست

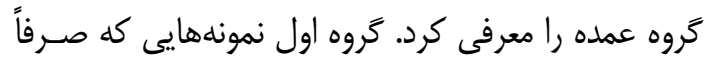

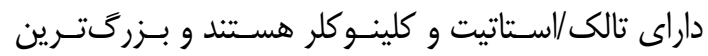

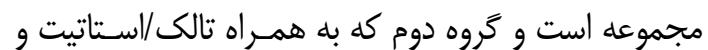

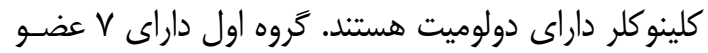

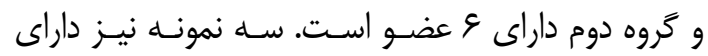

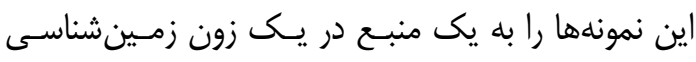

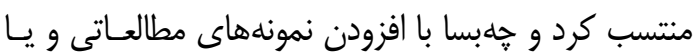

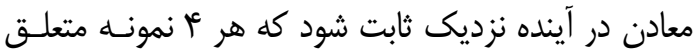

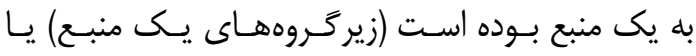
برعكس. جنين وضعيتى توسط الـرى فـرام[36] در مـورد ابسيدينهاى نمرودداغ و بينگگول در آسياى صغير خَزارش

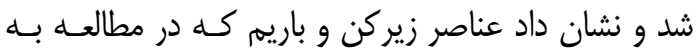
روش XRF جهت شناسـايى منبـع ابسـيدينهـا اسـتفاده

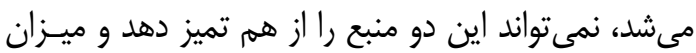
اين دو عنصر در هر دو منبع برابر است. همجنين بايد اشاره كرد كه در اين نمونسهــا ميـزان اكسيد آهن يايينتر از هاء است. بالا بودن ميزان آهن در كرد

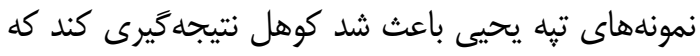

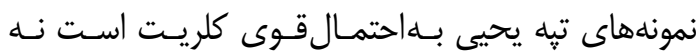

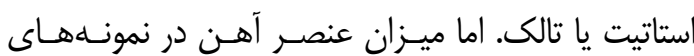
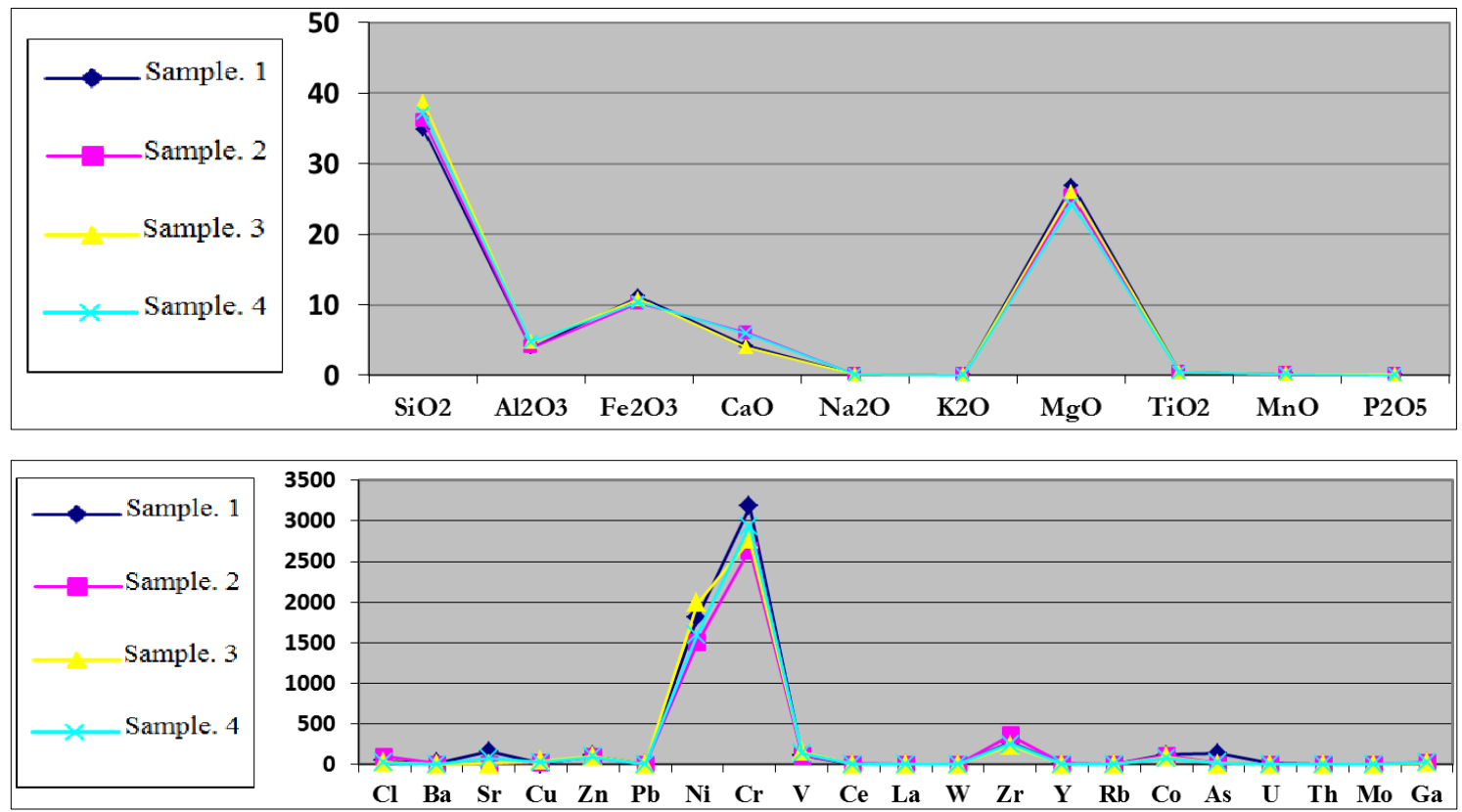

شكل سّ: نمودار برهم اندازى نمونههاى شادياخ در نرم|فزار

Fig. 3: Overlap graph of Shdyakh's samples elements

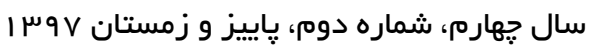


جدول "ا: نتايج آزمايش عا قطعه ظرف سنگى شادياخ به روش XRD

Table 3: Analyses result of 16 pieces Soft stone vessels of Shadyakh by XRD

\begin{tabular}{|c|c|c|c|c|c|c|}
\hline No & Talc & Clinochlore & Graftonite & Dolomite & Britholite & $\begin{array}{l}\text { Magnesium } \\
\text { carbonate }\end{array}$ \\
\hline 1 & $\sqrt{ }$ & $\sqrt{ }$ & - & - & - & - \\
\hline 2 & $\sqrt{ }$ & $\sqrt{ }$ & $\sqrt{ }$ & - & - & - \\
\hline 3 & $\sqrt{ }$ & $\sqrt{ }$ & - & $\sqrt{ }$ & - & - \\
\hline 4 & $\sqrt{ }$ & $\sqrt{ }$ & - & - & $\sqrt{ }$ & - \\
\hline 5 & $\sqrt{ }$ & $\sqrt{ }$ & - & $\sqrt{ }$ & - & - \\
\hline 6 & $\sqrt{ }$ & $\sqrt{ }$ & - & - & - & $\sqrt{ }$ \\
\hline 7 & $\sqrt{ }$ & $\sqrt{ }$ & - & $\sqrt{ }$ & - & - \\
\hline 8 & $\sqrt{ }$ & $\sqrt{ }$ & - & $\sqrt{ }$ & - & - \\
\hline 9 & $\sqrt{ }$ & $\sqrt{ }$ & - & $\sqrt{ }$ & - & - \\
\hline 10 & $\sqrt{ }$ & $\sqrt{ }$ & - & - & - & - \\
\hline 11 & $\sqrt{ }$ & $\sqrt{ }$ & - & - & - & - \\
\hline 12 & $\sqrt{ }$ & $\sqrt{ }$ & - & - & - & - \\
\hline 13 & $\sqrt{ }$ & $\sqrt{ }$ & - & $\sqrt{ }$ & - & - \\
\hline 14 & $\sqrt{ }$ & $\sqrt{ }$ & - & - & - & - \\
\hline 15 & $\sqrt{ }$ & $\sqrt{ }$ & - & - & - & - \\
\hline 16 & $\sqrt{ }$ & $\sqrt{ }$ & - & - & - & - \\
\hline \multicolumn{7}{|c|}{$\begin{array}{l}\text { Talc: } \mathrm{Mg}_{3} \mathrm{Si}_{4} \mathrm{O}_{10}(\mathrm{OH})_{2} \text { Ref. Code: } 00-002-0569 / \text { Clinochlore: }\left(\mathrm{MgFe}_{2}+\mathrm{Al}\right)_{6}\left[(\mathrm{OH}) 8 \text { - }(\mathrm{AlSi})_{4} \mathrm{O} 10\right] \text {, Ref. Code } \\
\text { :00-007-0078/ Graftonite :(}\left(\mathrm{Fe}^{2+} \mathrm{MnCa}\right)_{3}\left(\mathrm{PO}_{4}\right)_{2} \text { Ref. Code: } 01-073-1909 / \text { Dolomite: } \mathrm{CaMg}\left(\mathrm{CO}_{3}\right)_{2} \text { Ref. Code: } \\
\text { 00-001-0942/ Britholite :(CeCa })_{5}\left(\mathrm{SiO}_{4}\right)_{3} \mathrm{OH} \text {, Ref. Code: 00-046-1294/ Magnesium carbonate: }(\mathrm{MgCO}) \text {, Ref. } \\
\text { Code: 00-008-0479. }\end{array}$} \\
\hline
\end{tabular}

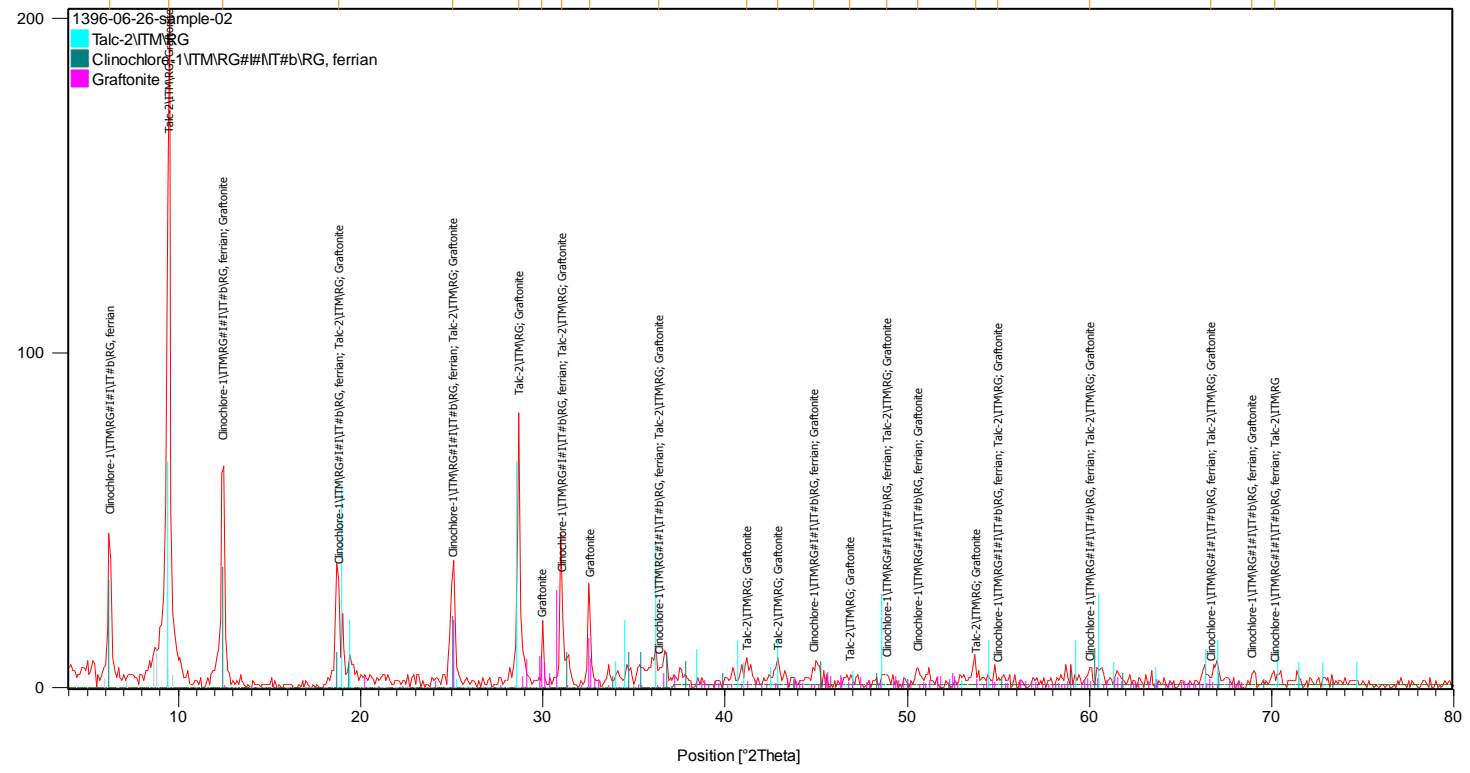

شكل عا: نمودار XRD (طيف) نمونه شماره r از نمونههاى باستانى شادياخ

Fig. 4: XRD spectrum Sample No. 2 from Shadyakh 


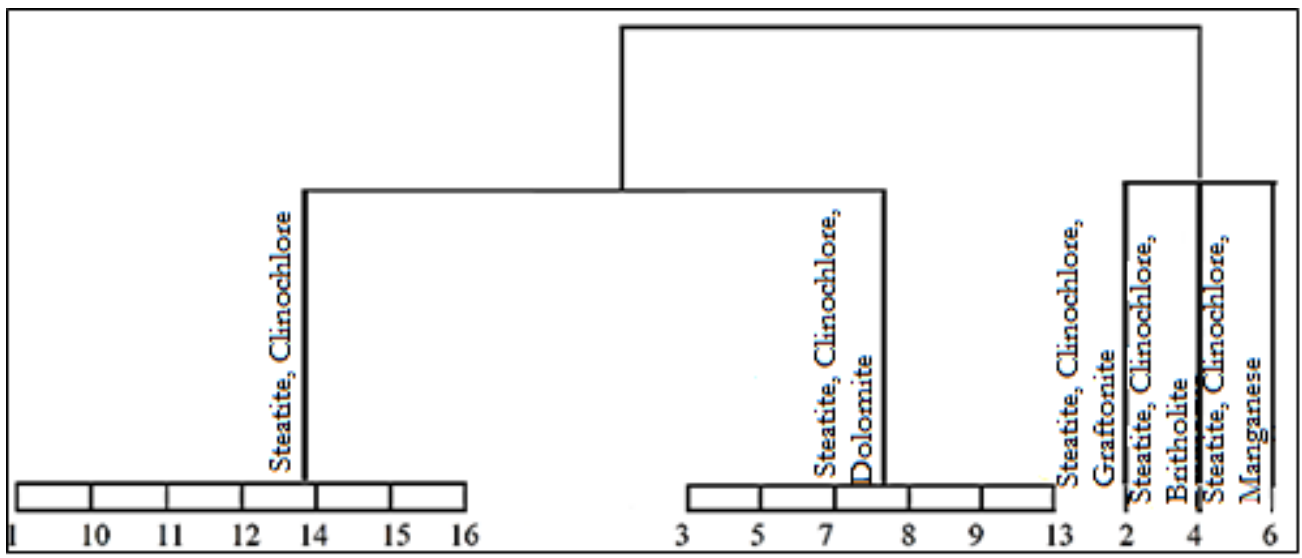

شكل ه: نمودار گروهبندى تركيبات نمونهاى مطالعه شده

Fig. 5: Graph of grouping of compounds of studied samples

دكرسانى سنغ هاى كربناته ايجاد شـده اسـت. در نمونـهـ

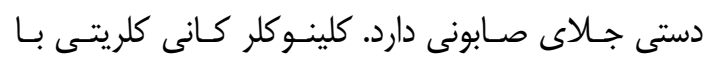

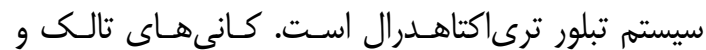

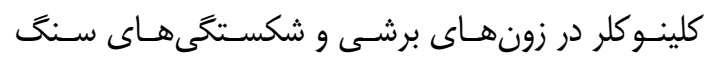
ميزبان تشكيل مى شوند و حاصل دگرسـانى هسـتند [37].

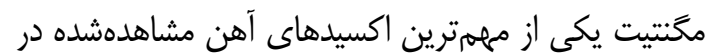

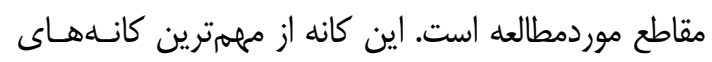
آهندار محسوب مىشود[38].
منغخنز، گرافتونيت و بريتوليت هستند كه جـدا از دو گــروه اشاره شده در بالا است (شكل ه).

SEM r-r مطالعه نمونهها به روش نمونه شماره ا شادياخ

اين نمونه ريزدانه و يورفيرى ويتروفيريك (شيشهاى) دارد.

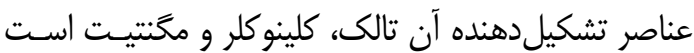
(شكل ج). تالك كانى است كه از دگرسانى سريانتين و يـا

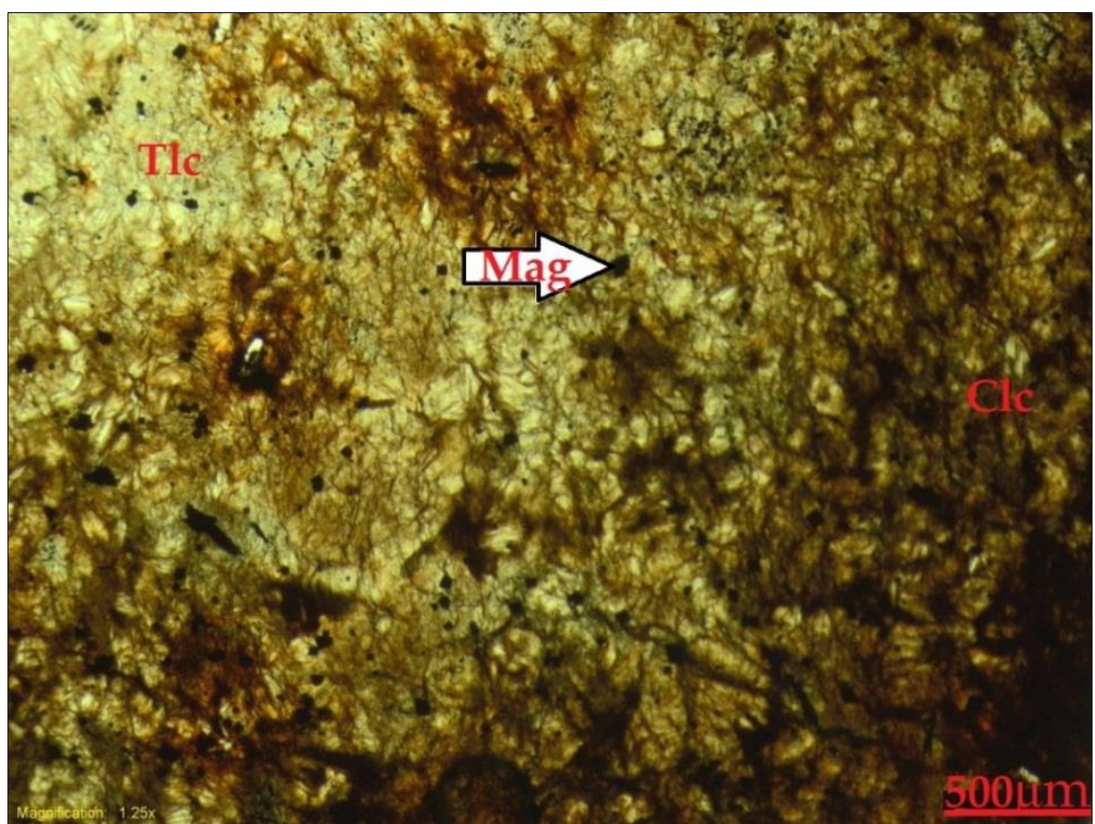

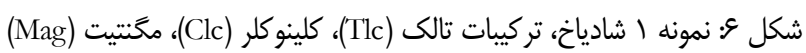
Fig. 6: Sample No.1, Talc, Clinochlore, Magnetite 


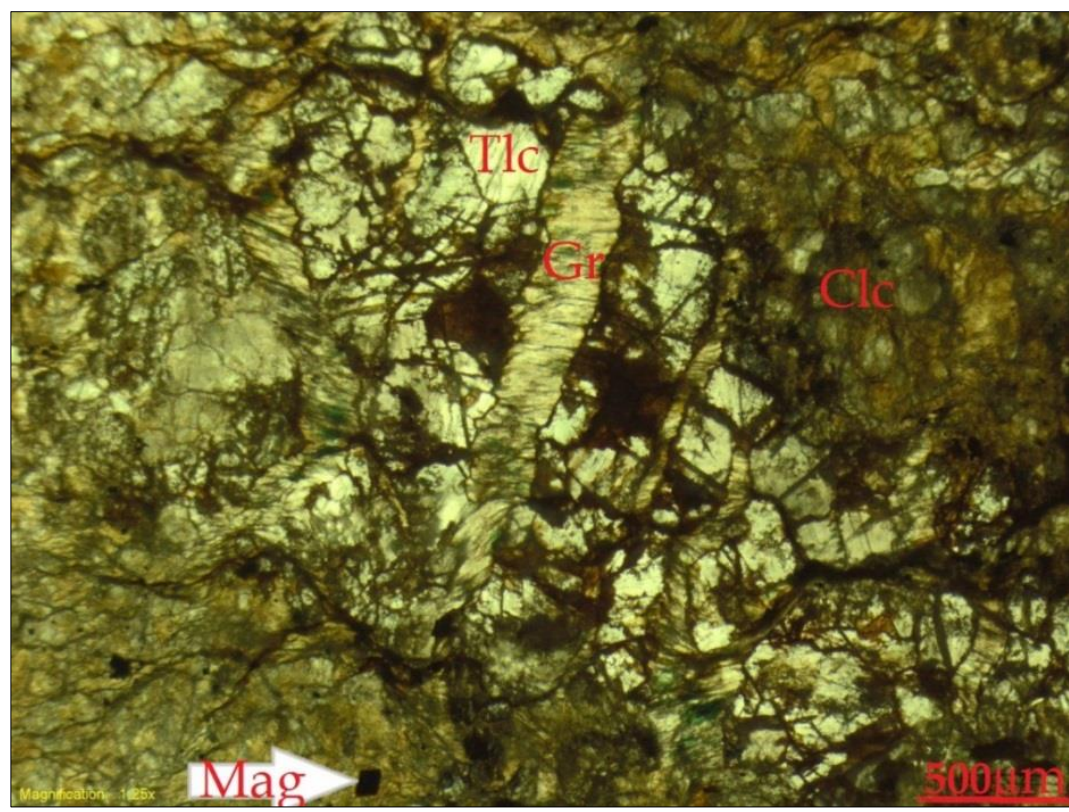

شكل V: نمونه r شادياخ، تركيبات تالك (Tlc)، كلينوكلر (Clc)، كرافتونيت (Gr))، مَّتتيت (Mag) (Mag) Fig.7: Sample No.2, Talc, Clinochlore, Graftonite, Magnetite

آن بايد بالاى هص٪ باشد. افـزون بــر ايـن آنجـهـ از نتـايج

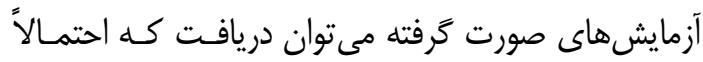

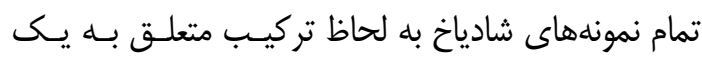
معدن و ساختار زمينشناسى است.

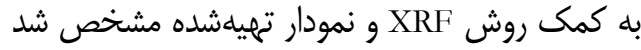

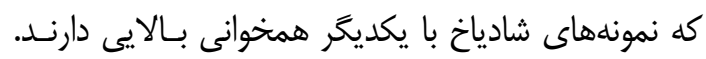

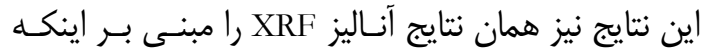

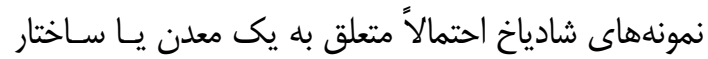

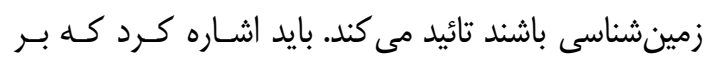

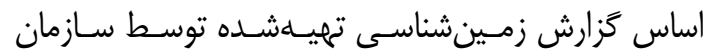
زمينشناسى كشور و مطالعات زمينشناسى ديخر در مـورد

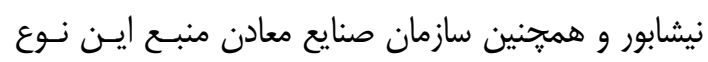

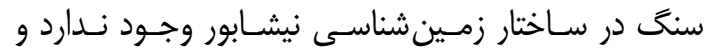

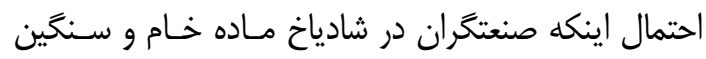

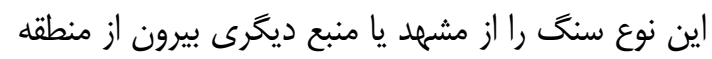

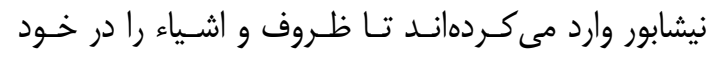

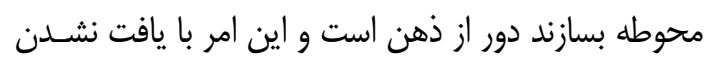

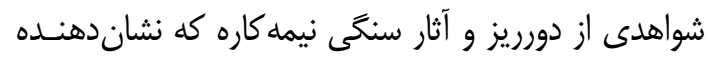
توليد محلى باشد تقويت مى شود.

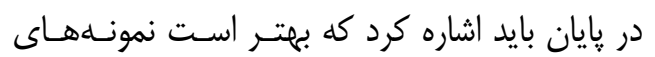

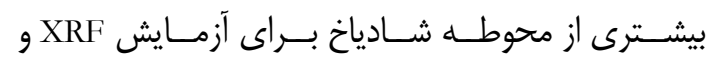

\section{ن انمونه شماره r شادياخ}

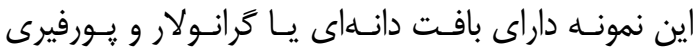
ويتروفيريك (شيشهاى) است. كانىهاى تشكيل دهنده آن آن

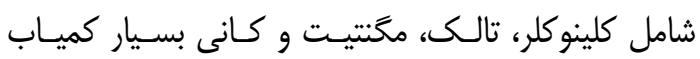

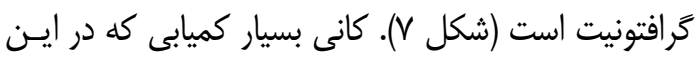

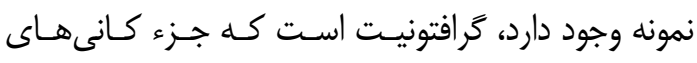

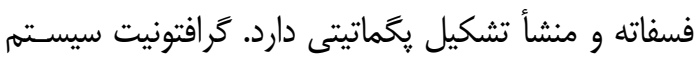
تبلور مونوكلينيك، سختى ضعيف، جلاى شيشه ایى -هرب دارد و شكل بلور آن منشورى است[37].

\section{ه. نتيجهد كيرى}

نتايج آزمايش نشان داد كه تالـى و كلينـوكر كـانىهـاى

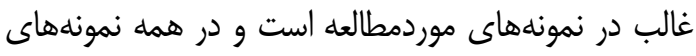

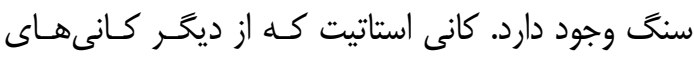

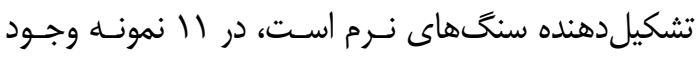

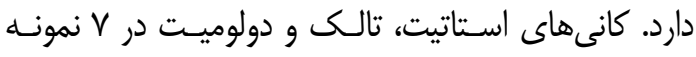

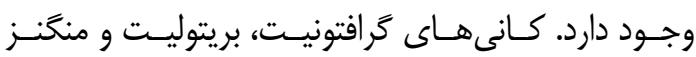

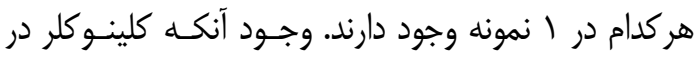

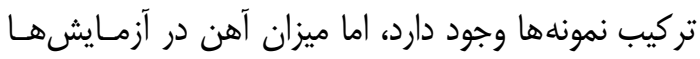

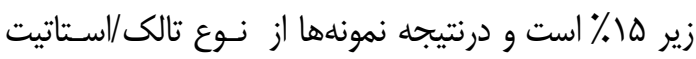

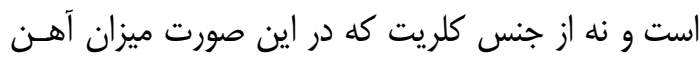

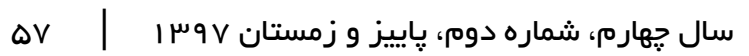


بركت ده. ايشان دستور دادند براى تهيه غذا از آن كوه

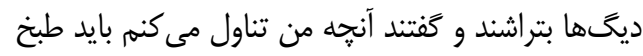

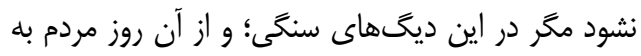
آن كوه راه يافتند[39].

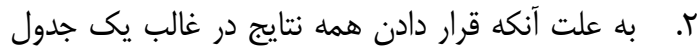

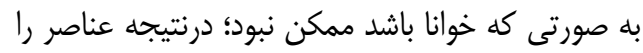

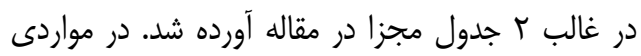

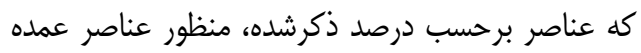

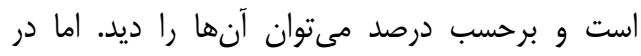

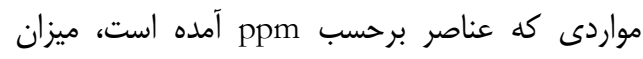
عنصر در ميليون هستند و عناصر نادر يا همان تريس

\section{References}

[1] Renfrew C, Dixon JE. Obsidian Hydration Dating. In: Taylor R., Aitken M., editors. Adv. Archaeol. Museum Sci., New York, London: 1977, p. 297-321.

[2] Abdi K. Obsidian in Iran from the Epipalaeolithic period to the Bronze Age. Persiens Antike Pr 2004:148-53.

[3] Aruz J. Intercultural style" carved chlorite objects. Art First Cities Third Millenn BC from Mediterr to Indus New York Metrop Museum Art P 2003:325-46.

[4] De Cardi B. Excavations at Bampur: a third millennium settlement in Persian Baluchistan, 1966. vol. 51. American Museum of National History; 1970.

[5] Seyed Sajadi SM. Indian-Continental Civilization. Tehran: SAMT Publication; 2009. [in Persian]

[سيدسجادى سيدمنصور. باستانشناسى شبه قاره تـاريخ

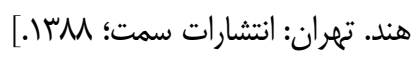

[6] Hole F, Flannery K V, Neely JA. Prehistory and human ecology of the Deh Luran Plain: an early village sequence from Khuzistan, Iran. University of Michigan; 1969.

[7] Hole F. Studies in the archeological history of the Deh Luran Plain: the excavation of Chagha Sefid. Museum of Anthropology, University of Michigan; 1977.

[8] Perrot J. Archaeological Report of Eight Seasons of Survey and Excavation at Shahdad (Lut Plain). In: Hakemi A, Musavi M. Tehran: Iranian Center for
يتروكر افى مطالعه شود تا بتوان نتايج مطمئنتـرى كسـب

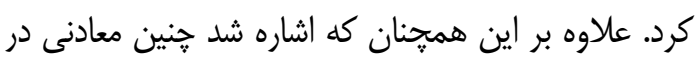

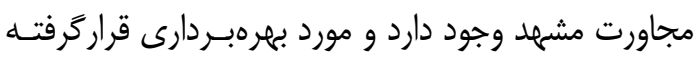

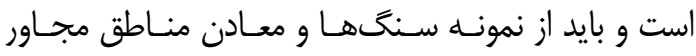

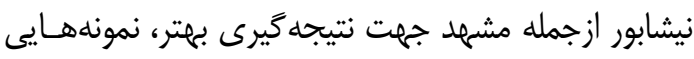
به ميزان لازم تهيه و مورد بررسى قرار كيرد.

$$
\begin{aligned}
& \text { بيىنوشتها }
\end{aligned}
$$

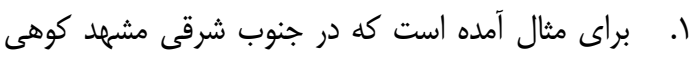

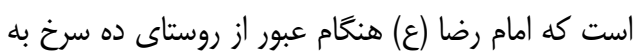

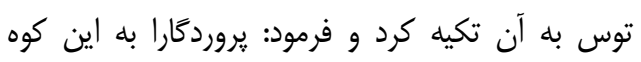

Archaeological Research; 2006. [in Persian]

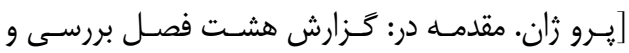

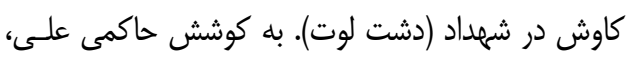

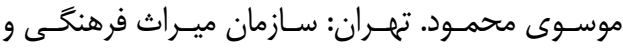

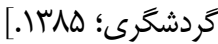

[9] Rafifar J aldi, Roberto M, Massiomo V. Aspects of drilling in Konar Sandal. In: Madjidzadeh Y, editor. First Int. Conf. Archaeol. Res. Jiroft, Kerman: Cultural Heritage, Handicrafts\& Tourism Organization of Kerman Province; 2008,127-44. [in Persian]

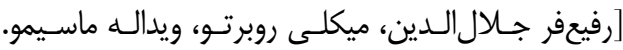

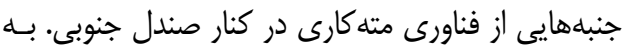

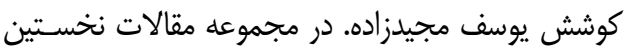

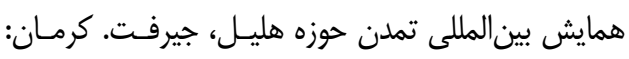

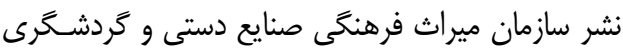

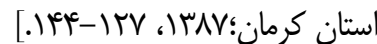

[10] Lamberg-Karlovsky CC. Excavations at Tepe Yahya, Iran, 1967-1969: Progress Report. American School of Prehistoric Research, Harvard University; 1970.

[11] Hakemi A. Shahdad: archaeological excavations of a bronze age center in Iran. vol. 27. IsMEO; 1997.

[12] Labbaf Khanaki M, Bakhtiari Shahri M. Report of the second season of excavation at Shadyakh. Neyshabour: 2001. [in Persian] [لبافخانيكى ميثه، بختيـارى شهرى محمـود. كَزارش

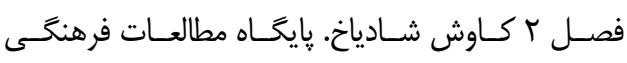

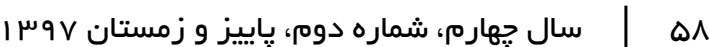




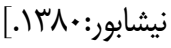

[13] Labbaf Khanaki R, Bakhtiari Shahri M. Report of the third season of excavation at Shadyakh, Neyshabour. Khorasan Razavi: 2002. [in Persian]

[لبافخانيكى رجبعلى، بختيارى شهرى محمود. تَز ارش

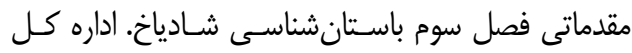

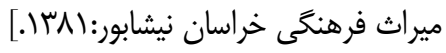

[14] Labbaf Khanaki R, Bakhtiari Shahri M. Report of the fourth season of excavation at Shadyakh. Neyshabour: 2003. [in Persian]

[لبافخانيكى رجبعلى، بختيارى شهرى محمود. تَزارش

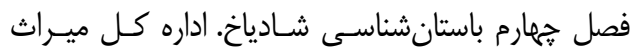

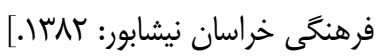

[15] Labbaf Khanaki R. Report of the sixth season of excavation at Shadyakh. Neyshabour: 2005. [in Persian]

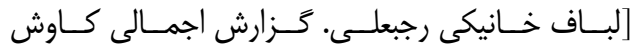

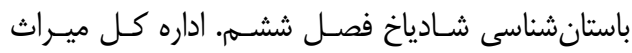

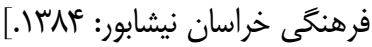

[16] Kohl PL, Harbottle G, Sayre E V. Physical and chemical analysis of soft stone vessels from southwest Asia. Archaeometry 1979;21:131-59.doi:

https://doi.org/10.1111/j.14754754.1979.tb00249.x

[17] De Caritat P, Hutcheon I. John L. Walshe Chlorite geothermometry. Clays Miner 1993;41:219-39.doi:

https://doi.org/10.1346/CCMN.1993.041 $\underline{0210}$

[18] Razani M. Archaeometry Investigations on the Black Stones Belong to Jiroft Civilization. MA Tesis Art University of Isfahan, 2010. [in Persian]

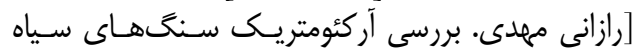

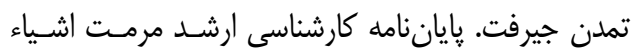

فرهنگى -تاريخى. دانشخاه هنر اصفهلان. •وسا.

[19] Emami M, Razani M, Soleimani NA, Madjidzadeh Y. New insights into the characterization and provenance of chlorite objects from the Jiroft civilization in Iran. J Archaeol Sci Reports 2017;16:194-204.doi: https://doi.org/10.1016/j.jasrep.2017.10.0 04

[20] Afsharinezhad H, Razani M. Structural Characterization and Preservation and Restoration of Chlorite dishes in the Jiroft cultural area. 11th Symp. Conserv. Restor.
Hist. Artifacts Archit. Decor. Tabriz: 2014. [in Persian]

[افشارىنـزاد حكيمـه، رازانى مهـــى ساختارشناسـى و

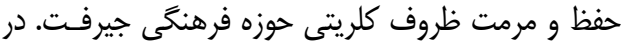

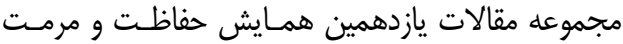

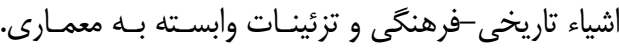

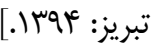

[21] Amini Birami F, Razani M, Asghari Kaljahi E, Emami, S, M A, Baghbanan A. Characterization of Pyroclastic Stones in the Cut Rock Historical Architecture of Kandovan Village. J Res Archaeom 2015;1:1-16. [in Persian]doi: https://doi.org/10.29252/jra.1.1.1

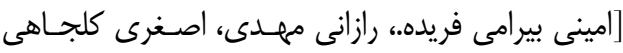
ابراهيه، امامى سيد محمد امين، باغبانان عليرضا. تحلئ ريليل

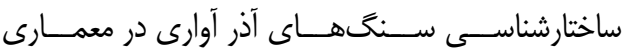

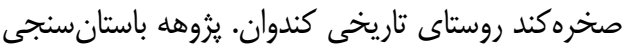
[..19-1: ! ! (1)

[22] Statistical Centre of Iran. Statistical annals of Khorasan Razavi Province 2015:60. [in Persian]

[مركز آمار ايران. سالنامه آمارى استان خراسـان رضـوى

$[.8 \cdot: 1494$

[23] Zarrinkob, Abdolhosein. History of Iranian people. Tehran: Amirkabir; 1985. [in Persian]

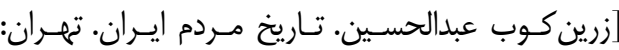

$$
\begin{aligned}
& \text { ميركبير؛ ثبعسا.] }
\end{aligned}
$$

[24] Yarshater E. Cambridge History of Iran, Vol. I: Seleucid, Parthian and Sassanian Periods. Translated by Anoushe H. Tehran: Amirkabir; 1989. [in Persian]

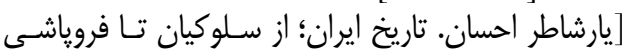

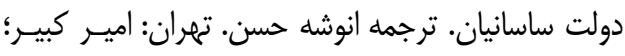

$[.1 \% \mathrm{H}$

[25] Canepa MP. Building a new vision of the past in the Sasanian Empire: The sanctuaries of Kayānsīh and the Great Fires of Iran. J Persianate Stud 2013;6:64 90.doi:

https://doi.org/10.1163/18747167$\underline{12341249}$

[26] Yaqubi A. Al-Baladan. Translated by Mohamad Ayati E. Tehran: Company Of, Translation and Publishing; 1987. [in Persian]

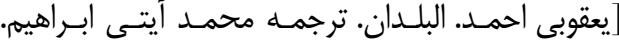

$$
\begin{aligned}
& \text { تهران: بنغاه ترجمه و نشر كتاب؛ عوبـا. }
\end{aligned}
$$

[27] Muqaddasi MA.S. The Best Divisions for 
Knowledge of the Regions. Translated by Monzavi A. Tehran: Koomesh; 2006. [in Persian]

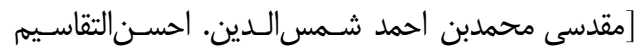

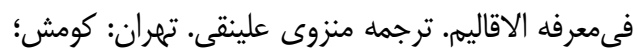

$[.1 \%$ No

[28] Haji Alilou S, Laleh H. Archaeological Survey of the Nishabur Cultural Zone from the Early Islamic Metallurgy Mining Viewpoint. Pazhohesh-Ha- Ye Bastanshenasi Iran 2014;3:101-20. [in Persian]

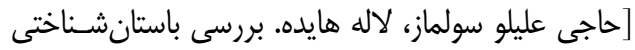

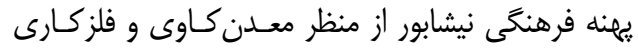

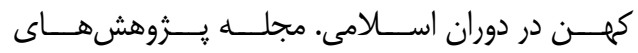

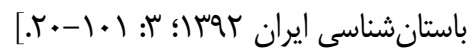

[29] Sani-ol Douleh MGK. Rahe Nejat. Tehran: Iranian History Press; 1984. [in Persian]

[صنيع الدوله مرتضـى قلى بـن على قلىى. راه نجـات. تهران: نشر تاريخ ايران؛ سعسا.

[30] Hedayat R ibn MH. Ajmal al-Tawarikh. Tabriz: 1909. [in Persian]

هدايت رضا قلى بن محمد هادى. اجمل التواريخ. تبريز:

[.ITM

[31] Khalaf Tabrizi MH. Borhan-e Ghate. Tehran: Amirkabir; 1878. [in Persian]

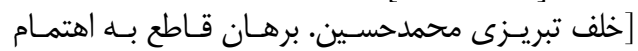

محمد معين. تهران: اميركبير؛

[32] Ibn Hawqal MA al-Q. Surat al-Ard (The face of the Earth). Translated by Shoar J. Tehran: Amirkabir; 1987. [in Persian]

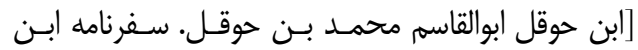
حوقل (ايران در صور الارض). ترجمه شعار جعفر. تمران:

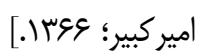

[33] Labbaf Khanaki R, Bakhtiari Shahri M. Report of the fifth season of excavation at Shadyakh, Neyshabour. Khorasan Razavi: 2011. [in Persian]

[لبافخانيكى رجبعلى، بختيارى شهرى محمود. تَزارش

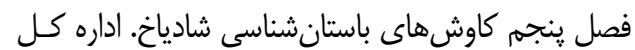

ميراث فرهنكى خراسان: • وسجا.]

[34] Sarhadi Dadiyan H, Pourzaghan V, Moradi H, Razani M. Traces of Indigenous Buff Pottery Industry of Shahr-I Sokhta; Using Semi-Quantitative Analysis of Elements XRF. J Res Archaeom 2015;1:47-54. [in Persian]doi: https://doi.org/10.29252/jra.1.1.47

[سرحدى داديان حسين، يورزرقان وحيد، مرادى حسـين،

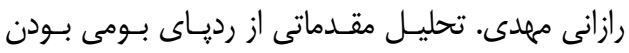

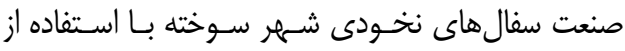

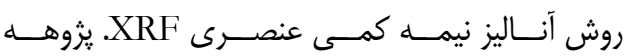

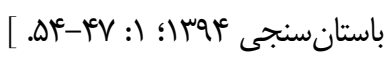

[35] Razani M, Conejero, Feli, Martinez Mansori Isfahani M, Afsharinezhad $\mathrm{H}$. Archaeometry, Thin Section Preparation, Mortars, Pottery, Soft \&, Weathered Rock. J Res Archaeom 2017;3:45-60. [in Persian] doi: https://doi.org/10.29252/jra.3.2.45

]رازانى مهدى، كونيخرو فلى مارتينز، منصورى اصـفهـانى

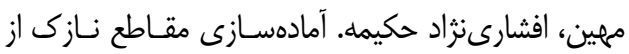
مواد متخلخل براى مطالعه با ميكروسكوض

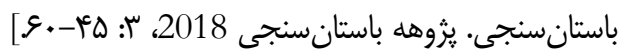

[36] Frahm E. Distinguishing Nemrut Dağ and Bingöl A obsidians: geochemical and landscape differences and the archaeological implications. J Archaeol Sci 2012;39:1436-44.doi:

https://doi.org/10.1016/i.jas.2011.12.038

[37] Klein C, Hurlbut CS. Manual of Mineralogy, edited by Farid Moore. Translated by Mer F, Modaberi S. Tehran: University Press; 2007. [in Persian]

[كلاين كورئليس، سرل هـارلبوت كورئليـوس. راهنمـاى

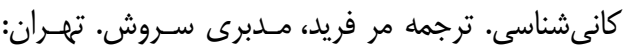

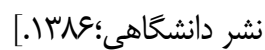

[38] Bayati Rad Y, Mirnejad H, Ghalamghash J. Distribution and Abundance of Rare Earth Elements in Magnetite from GolGohar Iron Ore Deposit, Sirjan, Kerman. Sci Q Journal, Geosci 2013;23:217-24. [in Persian]

فيياتىراد يلدا، ميرنزاد حسن، قلمقاش جليلى. يراكندكى و

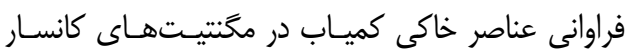

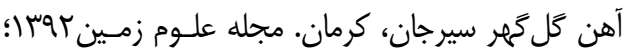

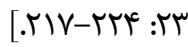

[39] Erfanmanesh J. Historical Geography migration of Imam Reza from Medina to Merv. Mashhad: Islamic Research Foundation of Astane Quds Razavi; 2003. [in Persian]

[عرفانمنش جليل. جغرافياى تاريخى هجرت امـام رضـا

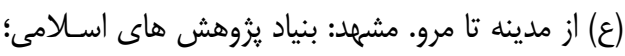

[.ITNT 


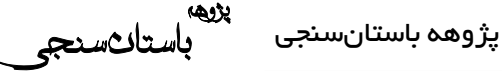

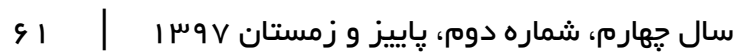

